\title{
Perspectives acquired through long-term epidemiological studies on the Great East Japan Earthquake
}

\author{
Toru Tsuboya ${ }^{1}$, Mariko Inoue ${ }^{2}$, Michihiro Satoh ${ }^{3}$ and Kei Asayama ${ }^{45^{*}}$ (D)
}

\begin{abstract}
The Great East Japan Earthquake (GEJE) and subsequent tsunamis that occurred in 2011 caused extensive and severe structural damage and interrupted numerous research activities; however, the majority of such activities have been revived, and further public health researches and activities have started to follow the population affected by the disaster. In this mini-review, we overview our recent activities regarding epidemiologic studies in Miyagi Prefecture, the region most affected by the GEJE. Through our study processes, we were able to identify the particular characteristics of vulnerable populations, and provide ideas that may help save lives and reduce the amount of damage caused by a future disaster. Long-term follow-up and care of survivors is essential in affected areas, and health professionals should pay particular attention to various diseases, e.g., cardiovascular complications and mental disorders. Furthermore, building up resilience and social relationships in the community is beneficial to survivors. Ongoing cohort studies conducted before disasters can help minimize biases regarding the survivors' pre-disaster information, and emerging cohort studies after disasters can find potential helpful novel indices. To identify characteristics of vulnerable populations, save lives, and reduce the amount of damage caused by a future disaster, constant research that is consistently improved by new data needs to be performed.
\end{abstract}

Keywords: Great East Japan Earthquake, Tsunami, Cohort study, Resilience, Disaster

\section{Introduction}

The Great East Japan Earthquake (GEJE) and subsequent tsunamis occurred at 14:46 on March 11, $2011[1,2]$. The GEJE had a magnitude of 9.0 on the Richter scale, making it the most powerful earthquake in Japan and the fourth in the world since modern record-keeping began in 1900. The GEJE triggered a series of devastating tsunamis, that caused extensive and severe structural damage and interrupted numerous research activities, such as ongoing community-based cohort and epidemiological studies. However, the majority of these research activities have since been revived, and further public health research and

\footnotetext{
* Correspondence: kei@asayama.org

Part of this work was presented at the 86th Annual Meeting of the Japanese Society for Hygiene (Asahikawa, Japan 2016).

${ }^{4}$ Department of Hygiene and Public Health, Teikyo University School of Medicine, Tokyo, Japan

${ }^{5}$ Department of Planning for Drug Development and Clinical Evaluation, Tohoku University Graduate School of Pharmaceutical Sciences, 2-1

Seiryo-cho, Aoba-ku, Sendai 980-8575, Japan

Full list of author information is available at the end of the article
}

activities have started to follow the population most affected by the GEJE. Based on the recent seismological findings, a simple 'characteristic earthquake' model for the long-term forecast is difficult to apply, e.g., recurrence of Nankai Trough Earthquake with an interval of $\approx 100$ years has been identified but the sizes of recurrent earthquakes vary according to tsunami deposits [3]. We should therefore improve managing disaster risks for a resilient future (https://www.gfdrr.org/sites/ gfdrr/files/sendai/sendai.html (2016.10.17)). In this minireview, we provide a brief overview of our recent activities based on epidemiological studies conducting in Miyagi Prefecture, the region most affected by the disaster, and discuss what we need for saving lives and reducing damage after a disaster. We further aim to specify a significance of consistent improvement of longitudinal studies. 


\section{Iwanuma project - social cohesion and mental health}

The Iwanuma Project $[4,5]$ is a part of the general population-based Japan Gerontological Evaluation Study (JAGES) [6, 7]. The JAGES was a nationwide study established in 2010 to prospectively examine the determinants of healthy aging [6]. Approximately $48 \%$ of Iwanuma City, which is located in a southern coastal area in Miyagi Prefecture, was inundated by the tsunamis after the GEJE (Table 1). Approximately 2.5 years after the disaster, we carried out a follow-up survey among 4,380 survivors in Iwanuma aged $\geq 65$ years old $[4,5]$.

Among the analytic sample of the Iwanuma residents, $38.0 \%$ reported losing loved ones such as friends or relatives, $59.0 \%$ reported damage to their property resulting from the GEJE, and $11.4 \%$ reported having symptoms of severe posttraumatic stress disorder, [4] which was measured using the Screening Questionnaire for Disaster-Related Mental Health [8]. Based on the spatial Durbin model, which can capture the spatial spillover association of community social cohesion, [9] social cohesion was significantly associated with a risk of posttraumatic stress disorder symptoms at both the individual-level (odds ratio [OR], 0.87; 95\% confidence interval [CI], 0.77-0.98) and community-level (OR, 0.75; 95\% CI, 0.63-0.90) [4]. Loss of loved ones and damaged housing at the individual level and an interruption in access to internal medicine and psychiatry services were also associated with a higher risk of posttraumatic stress disorder symptoms $(p<0.01)$ [4]. We would emphasize that our findings were not affected by recall bias because we obtained information on Iwanuma residents both before and after the GEJE. Social cohesion among neighbors may help to explain the community-level variations in the occurrence of posttraumatic stress disorder after natural disasters [4].

We further found associations between experiences of disaster-related damage and changes in depressive symptoms among survivors, [5] based on the dichotomous 15items Geriatric Depression Scale (GDS), which has been validated in both English [10] and Japanese [6]. We evaluated personal experiences of damage caused by the GEJE and tsunamis based on previous studies on mental health among survivors after natural disasters, in consideration of the local culture $[11,12]$. Among 3,464 eligible participants with complete data, the mean (SD) GDS scores at baseline and follow-up were 3.74 (3.5) and 3.84 (3.4), respectively. The changes in GDS scores between the two surveys were more pronounced among men than among women $(0.17$ versus 0.05$)$. Multivariateadjusted linear regression analysis showed that experiences of property loss were significantly associated with worsening GDS scores: the non-standardized coefficient of the model was 1.40 (95\% CI, 0.96-1.83) for total housing loss and 0.47 (95\% CI, 0.21-0.74) for loss of an automobile. The impact on loss of family members was also significant, whereas the effect size of the GDS was relatively small, at $0.23(95 \% \mathrm{CI}$, $0.02-0.44)$. Both loss of employment $(n=186,5.1 \%)$

Table 1 Population sampling methods and characteristics of each study

\begin{tabular}{|c|c|c|c|}
\hline & Iwanuma Project $^{\mathrm{a}}[4,5]$ & $\begin{array}{l}\text { Health and Life Revival Council } \\
\text { in Ishinomaki District }(\mathrm{RCI}) \\
{[13,14,16-18]}\end{array}$ & $\begin{array}{l}\text { Tohoku Study of Child Development } \\
\text { (TSCD) }[2,19-23]\end{array}$ \\
\hline Place of municipality & Iwanuma & Ishinomaki & $\begin{array}{l}\text { Sendai and the Sanriku coastal areas of Miyagi } \\
\text { Prefecture }\end{array}$ \\
\hline $\begin{array}{l}\text { Population of the municipality } \\
\text { in Sep } 2015\end{array}$ & 44,149 & 148,968 & $>1$ million \\
\hline $\begin{array}{l}\text { Damage from GEJE and subsequent } \\
\text { tsunamis on Mar } 2011\end{array}$ & $\begin{array}{l}187 \text { died, } 48 \% \text { of the land } \\
\text { was inundated. }\end{array}$ & $\begin{array}{l}\text { 3,055 died, } 420 \text { missing, } 270 \text { certified } \\
\text { as disaster-related death. }\end{array}$ & $\begin{array}{l}\text { On TSCD, } 2 \text { mothers and } 3 \text { children died, } 10 \\
\text { families missing, the investigation was } \\
\text { suspended for } 5 \text { months. }\end{array}$ \\
\hline Sampling frame & 8,576 residents $\geq 65$ years & $\begin{array}{l}\approx 8,700 \text { survivor families living only on } \\
\text { the } 2 \text { nd floor of their damaged houses }\end{array}$ & $\begin{array}{l}\text { Neonates born at } 36-42 \text { weeks of gestation } \\
\text { with a birth weight of } \geq 2400 \mathrm{~g} \text {. }\end{array}$ \\
\hline Recruitment period & Aug 2010 & $\begin{array}{l}\text { Oct } 2011 \text { to Mar } 2012 \text { as 1st-term } \\
\text { survey }\end{array}$ & Jan 2001 to Sep 2005 \\
\hline Latest follow-up period & Oct 2013 to Jan 2014 & $\begin{array}{l}\text { Apr } 2013 \text { to Jan } 2014 \text { as 2nd-term } \\
\text { survey }\end{array}$ & Mar 2013 as the 7-year-old survey \\
\hline $\begin{array}{l}\text { Number in each cohort } \\
\text { database }\end{array}$ & 4,380 survivors & $\begin{array}{l}4,176 \text { households (1st-term); 4,023 } \\
\text { (2nd-term) }\end{array}$ & $\begin{array}{l}\text { 1,348 mother-offspring pairs from } 3 \text { maternity } \\
\text { hospitals }\end{array}$ \\
\hline Follow-up rate & $82.1 \%$ & n/a (2 surveys not yet fully linked) & $70.7 \%$ \\
\hline Outcome reported & $\begin{array}{l}\text { PTSD symptomatology, } \\
\text { mental health, physical } \\
\text { function, social activies }\end{array}$ & $\begin{array}{l}\text { Sleep problems, psychological distress, } \\
\text { symptoms, access to health services }\end{array}$ & $\begin{array}{l}\text { Home and conventional blood pressure, verbal, } \\
\text { performance, and full-scale IQ, autonomic } \\
\text { nervous indicators }\end{array}$ \\
\hline
\end{tabular}


and disruption of access to psychiatric care $(n=17$, $0.5 \%)$ were also associated with worsening GDS scores $(p<0.0001)$. In a community-dwelling elderly population, loss of employment, disruption of access to psychiatric care, and personal experiences of property damage predict a worsening of depressive symptoms, and have a more pronounced and lingering impact compared with experiencing the loss of a loved one [5].

\section{Health and life revival council in Ishinomaki District - community support}

Ishinomaki is one of the municipalities most severely damaged from the GEJE and subsequent tsunamis (Table 1) [13, 14]. After the GEJE, approximately 8,700 families in Ishinomaki remained at home, despite serious structural damage; many of these residents were living entirely on the second floor of their homes because the tsunami had completely swept away everything on the first floor $[13,14]$. This vulnerable population, referred to as the stay-at-home victims, was provided with less support by governmental agencies than those living in temporary shelters. To identify and evaluate stay-at-home survivors for providing more rapid and appropriate support in response to their needs, the Health and Life Revival Council in Ishinomaki District (RCI) conducted a face-to-face survey. We used a semi-structured questionnaire composed of the following three sections: household demographics; social background; and health condition of individuals most in need of medical support. The firstterm survey was started approximately 6 to 12 months after the GEDE (Table 1) [14].

Initially, data from 4,176 households were analyzed, with 4,023 household members agreeing to be interviewed using the written form in the first-term and future surveys [14]. Factors associated with sleep difficulties which frequently begin as stress-related phenomena including natural disaster [15] were loss of pleasure in life (OR, 1.37; 95\% CI, 1.07-1.76), living on a pension (versus living on salary: OR, 1.58; 95\% CI, 1.09-2.27) or public livelihood assistance (versus living on salary: OR, 4.40; 95\% CI, 1.53-12.65), or women (OR, 2.67; 95\% CI, 2.07-3.46) [14]. Interacting with neighbors by visiting one another was positively associated with sleep (OR, 0.42; 95\% CI, 0.24-0.74) [14]. Among survivors living at home around 2 years after the GEJE, participants with emotional social support (OR, 2.05; 95\% CI, 1.35-3.11) and informational social support (OR, 1.55; 95\% CI, 1.082.21) had lower rates of sleep difficulties, [16] suggesting that relatively strong neighborhood networks help prevent sleep difficulties. Loss of pleasure in life (OR, 1.25 ; $95 \% \mathrm{CI}, 1.00-1.57)$, changes in family structure (OR, 1.46; 95\% CI, 1.15-1.85), and changes in work status (OR, 1.30; 95\% CI, 1.06-1.59) were also significant factors associated with psychological distress [17].
Contrary to the hypothesis, the elderly ( $>65$ years) were more likely to have close neighbors and social/family interactions; non-elderly men living alone represented the highest proportion of people without social/family interactions, and persons living alone were less likely to have social/family interactions [18]. Strengthening social ties before and after disasters is important in building a resilient community capable of supporting the physical and mental health of its citizens.

\section{The Tohoku study of child development - comprehensive development of children}

The Tohoku Study of Child Development (TSCD) is a prospective birth cohort study primarily carried out to investigate the potential effects of perinatal exposure to environmental pollutants on the neurobehavioral development of children (Table 1) [19, 20]. After conducting periodic surveys, self-measured home blood pressure of children at 7 years of age was recorded; however, the GEJE caused a disruption in the data collection among those in the affected rural coastal areas [2, 21]. Although several participants were victimized (Table 1), [2] further research equipment, such as home blood pressure devices, were supplied relatively quickly, and data were recovered from a backup system as well as from the internal storage of each device, and the examinations were successfully resumed 5 months after the GEJE [2].

Maternal gestational hypertension did not affect home blood pressure in offspring, but it did strongly affect maternal home blood pressure, even 7 years after giving birth [22]. Home blood pressure among children with 7 years of age who received long-term (mean, 11.3 months) breastfeeding as a major source of nutrition was significantly lower than that among children who received short-term (mean, 5.1 months) breastfeeding (92.9/55.1 versus $94.7 / 56.4 \mathrm{~mm} \mathrm{Hg}$ systolic/diastolic blood pressure, respectively; $p=0.006 / 0.04$ ), suggesting that long-term breastfeeding had a protective effect against elevated blood pressure even in young children [23]. Furthermore, Tatsuta and colleauges assessed the neurodevelopmental effects of the GEJE [2]. Verbal intelligence quotient (IQ) at 7 years of age was significantly lower in a post-disaster group than in a pre-disaster group after the adjustment of preceding neurodevelopmental scores taken at 32 and 40 month olds $(p=0.001)$. In contrast, no significant differences were found in performance IQ, full-scale IQ, or autonomic nervous indicators $(p=0.053)$. This finding implies the indispensable effect of interrupted schooling [2].

The TSCD offered the opportunity to start a new line of longitudinal research into cardiovascular risk factors, such as blood pressures, as measured by conventional and self-measured at home in children from childhood to adolescence along with their mothers [21]. The TSCD 
is currently investigating the comprehensive health and development of children, including the long-term multilateral impact of the inevitable effects of the disaster [2].

\section{Other studies in Miyagi Prefecture - hypertension and diabetes}

Our research group has engaged in other collaborative research projects, such as local hospital-based surveys. Satoh and coworkers compared home blood pressure just before and after the GEJE in 142 hypertensive patients (40.8\% women; mean age, 68.1 years) [24]. The mean home systolic blood pressure of $126.9 \mathrm{~mm} \mathrm{Hg}$ just before the GEJE increased to $129.3 \mathrm{~mm} \mathrm{Hg}$ just after the GEJE. This increase remained significant 2 weeks after $(p=0.03)$ but disappeared by 4 weeks after the GEJE $(p=0.2)$. Among the 142 hypertensive patients, only 10 could measure their home blood pressure in the morning before the GEJE and during the subsequent 3 days after the GEJE. A steep elevation in home blood pressure was observed in those 10 patients, with the difference of $11.6 \mathrm{~mm} \mathrm{Hg}$ in home systolic blood pressure between the day of and the day after the GEJE $(p=0.02)$ [24].

Tanaka and colleagues investigated the impact of the GEJE on glycemic control based on 497 diabetic patients who had been followed at hospitals in the devastated Tohoku area [25]. Notably, the HbA1c levels of the diabetic patients were not elevated at 1 month after, and were significantly decreased at 3 months after as compared with before the GEJE [25]. This might have been the result of weight loss due to energy restrictions. Meanwhile, impaired endogenous insulin secretory capacity was associated with worsening of glycemic control after the GEJE [26]. The increased blood pressure or worsening of glycemic control might have led to an increase in the risk of cardiovascular disease just after the disaster [27, 28].

However, these studies [24-26] were only based on participants who could measure their blood pressure at home or visit clinics immediately after the GEJE. Survivors after a disaster would be expected to have higher cardiovascular risk because they cannot afford to take care of their health due to the loss of their home or loved ones. However, there are limitations in investigating the precise effects of a disaster on such survivors unless pre-disaster health data are available. For the management of hypertension in disaster conditions, a special network system for supporting continuous self-measurement of home blood pressure has been proposed [28]. Although it is impossible to monitor everyone after a large-scale disaster, daily home blood pressure measurement among survivors would be useful for investigating the effects of a disaster in relation to cardiovascular complications $[24,29]$.

\section{Perspectives}

We reviewed several studies in which we have taken part in on social, $[4-6,13,14,16-18]$ birth, $[2,19-23]$ and cardiovascular [21-27] epidemiologies regarding the GEJE. Through these study processes, we could help identify same particular characteristics of vulnerable populations and provide further ideas for saving lives and reducing damage after future disasters, e.g., by building social capital or social networks within communities. To ensure the ability to respond to such a disaster promptly, our findings can also assist in building a model for collaboration between academic institutions and non-governmental as well as governmental organizations. Both long-term follow-up and care of survivors in the affected areas are essential, and health professionals should pay special attention to various diseases such as cardiovascular complications and mental disorders. Besides providing sufficient medical care, building up resilience and social relationships in the community is expected to be beneficial to survivors. Ongoing cohort studies before disasters [2, 4-6, 19-23] can minimize biases regarding pre-disaster information for survivors, whereas emerging cohort studies after disasters $[13,14,16-18,24-27]$ can identify potentially useful novel indices. Constant research that is consistently improved by new data, therefore, needs to be performed.

\section{Acknowledgements \\ We would like to express our gratitude to all the staff members of the Iwanuma Project, the Health and Life Revival Council in Ishinomaki District, and the Tohoku Study of Child Development for their valuable contributions in relation to data collection and database management. We also wish to thank all of the participants in these studies.}

\section{Funding}

The JAGES project was supported by the NIH (R01 AG042463); Grant-in-Aid for Scientific Research $(23243070,22390400,24390469)$ from the Japanese Ministry of Education, Culture, Sports, Science and Technology (MEXT); Health Labour Sciences Research Grant (H24-Choju-Wakate-009); the Center for Wellbeing and Society, Nihon Fukushi University; and MEXT-Supported Program for the Strategic Research Foundation at Private Universities.

Teikyo University Graduate School of Public Health was supported by the Japan Public Health Society through a Special Grant for public health in the Great East Japan Earthquake in 2012.

The Tohoku Study of Child Development was supported by Grants for Scientific Research (23390171) from MEXT, Japan; a Grant-in-Aid for Japan Society for the Promotion of Science (JSPS) fellows (25*7756 and 25*9328); the Ministry of Health, Labour and Welfare, Japan; the Ministry of the Environment, Japan; and the Grant for Environmental Research Projects from the Sumitomo Foundation.

KA received the 2015 Japanese Society for Hygiene research grant for young investigators' project on behalf of all coauthors. All funding sources did not have any role in the design and conduct of the study, the collection, management, analysis, or interpretation of the data, the preparation, review, or approval of the manuscript, or the decision to submit the manuscript.

\section{Authors' contributions}

KA conceived and designed this review. TT, MI, KA, and MS contributed to the design and to the collection and interpretation of the data in Iwanuma project, the RCl, the TSCD, and other studies in Miyagi Prefecture,

respectively. $\Pi$ and $K A$ wrote the first draft of the review. All authors made 
critical revision of the manuscript for important intellectual content. All authors read and approved the final manuscript.

\section{Competing interests}

The authors declare that they have no competing interests.

\section{Publisher's Note}

Springer Nature remains neutral with regard to jurisdictional claims in published maps and institutional affiliations.

\section{Author details}

${ }^{1}$ Liaison Center for Innovative Dentistry / Department of International and Community Oral Health, Tohoku University Graduate School of Dentistry, 4-1, Seiryo-cho, Aoba-ku, Sendai 980-0872, Japan. ${ }^{2}$ Graduate School of Public Health, Teikyo University, 2-11-1 Kaga, Itabashi-ku, Tokyo 173-8605, Japan. ${ }^{3}$ Division of Public Health, Hygiene and Epidemiology, Faculty of Medicine, Tohoku Medical and Pharmaceutical University, 4-4-1 Komatsushima, Aobaku, Sendai 981-8558, Japan. ${ }^{4}$ Department of Hygiene and Public Health, Teikyo University School of Medicine, Tokyo, Japan. ${ }^{5}$ Department of Planning for Drug Development and Clinical Evaluation, Tohoku University Graduate School of Pharmaceutical Sciences, 2-1 Seiryo-cho, Aoba-ku, Sendai 980-8575, Japan.

Received: 26 June 2016 Accepted: 4 March 2017

Published online: 15 March 2017

\section{References}

1. Ishigaki A, Higashi H, Sakamoto T, Shibahara S. The Great East-Japan Earthquake and devastating tsunami: an update and lessons from the past Great Earthquakes in Japan since 1923. Tohoku J Exp Med. 2013:229:287-99.

2. Tatsuta N, Nakai K, Satoh H, Murata K. Impact of the Great East Japan Earthquake on Child's IQ. J Pediatr. 2015;167:745-51.

3. Satake K. Geological and historical evidence of irregular recurrent earthquakes in Japan. Philos Trans A Math Phys Eng Sci. 2015;373. doi:10 1098/rsta.2014.0375.

4. Hikichi H, Aida J, Tsuboya T, Kondo K, Kawachi I. Can Community Social Cohesion Prevent Posttraumatic Stress Disorder in the Aftermath of a Disaster? A Natural Experiment From the 2011 Tohoku Earthquake and Tsunami. Am J Epidemiol. 2016;183:902-10.

5. Tsuboya T, Aida J, Hikichi H, Subramanian SV, Kondo K, Osaka K, et al. Predictors of depressive symptoms following the Great East Japan earthquake: A prospective study. Soc Sci Med. 2016;161:47-54.

6. Fujiwara T, Kondo K, Shirai K, Suzuki K, Kawachi I. Associations of childhood socioeconomic status and adulthood height with functional limitations among Japanese older people: results from the JAGES 2010 Project. J Gerontol A Biol Sci Med Sci. 2014:69:852-9.

7. Saito M, Kondo K, Kondo N, Abe A, Ojima T, Suzuki K, et al. Relative deprivation, poverty, and subjective health: JAGES cross-sectional study. PloS one. 2014;9:e111169.

8. Fujii S, Kato H, Maeda K. A simple interview-format screening measure for disaster mental health: an instrument newly developed after the 1995 Great Hanshin Earthquake in Japan-the Screening Questionnaire for Disaster Mental Health (SQD). Kobe J Med Sci. 2007;53:375-85.

9. Elhorst JP. Applied spatial econometrics: raising the bar. Spat Econ Anal. 2010;5:9-28.

10. Yesavage JA, Brink TL, Rose $T L$, Lum $O$, Huang $V$, Adey M, et al. Development and validation of a geriatric depression screening scale: a preliminary report. J Psychiatr Res. 1982;17:37-49.

11. van Griensven F, Chakkraband ML, Thienkrua W, Pengjuntr W, Lopes Cardozo B, Tantipiwatanaskul P, et al. Mental health problems among adults in tsunami-affected areas in southern Thailand. JAMA. 2006;296:537-48.

12. Frankenberg E, Friedman J, Gillespie T, Ingwersen N, Pynoos R, Rifai IU, et al. Mental health in Sumatra after the tsunami. Am J Public Health. 2008:98:1671-7.

13. Ishiguro A, Togita $Y$, Inoue M, Ohkubo T, Yano E. Identification of disastervulnerable communities by use of census data prior to the Great East Japan Earthquake. Disaster Med Public Health Prep. 2015;9:19-28.

14. Matsumoto S, Yamaoka K, Inoue M, Muto S, Teikyo Ishinomaki Research Group, Health, Life Revival Council in the Ishinomaki district. Social ties may play a critical role in mitigating sleep difficulties in disaster-affected communities: a cross-sectional study in the Ishinomaki area, Japan. Sleep. 2014;37:137-45.
15. Davidson LM, Fleming R, Baum A. Chronic stress, catecholamines, and sleep disturbance at Three Mile Island. J Human Stress. 1987:13:75-83.

16. Matsumoto S, Yamaoka K, Inoue M, Inoue M, Muto S, Teikyo Ishinomaki Research Group. Implications for Social Support on Prolonged Sleep Difficulties among a Disaster-Affected Population: Second Report from a Cross-Sectional Survey in Ishinomaki, Japan. PloS One. 2015;10:e0130615.

17. Furukawa H, Takeuchi T, Yano E, Muto S. Factors influencing psychological distress after the Great East Japan Earthquake and Tsunami. J Community Psychol. 2015;43:521-6.

18. Inoue M, Matsumoto S, Yamaoka K, Muto S. Risk of social isolation among Great East Japan Earthquake survivors living in tsunami-affected Ishinomaki, Japan. Disaster Med Public Health Prep. 2014;8:333-40.

19. Suzuki K, Nakai K, Sugawara T, Nakamura T, Ohba T, Shimada M, et al. Neurobehavioral effects of prenatal exposure to methylmercury and PCBs, and seafood intake: neonatal behavioral assessment scale results of Tohoku study of child development. Environ Res. 2010;110:699-704.

20. Nakai K, Suzuki K, Oka T, Murata K, Sakamoto M, Okamura K, et al. The Tohoku Study of Child Development: A cohort study of effects of perinatal exposures to methylmercury and environmentally persistent organic pollutants on neurobehavioral development in Japanese children. Tohoku J Exp Med. 2004:202:227-37.

21. Asayama K, Staessen JA, Hayashi K, Hosaka M, Tatsuta N, Kurokawa N, et al. Mother-offspring aggregation in home versus conventional blood pressure in the Tohoku Study of Child Development (TSCD). Acta Cardiol. 2012;67:449-56

22. Hosaka M, Asayama K, Staessen JA, Tatsuta N, Satoh M, Kikuya M, et al. Relationship between maternal gestational hypertension and home blood pressure in 7-year-old children and their mothers: Tohoku Study of Child Development. Hypertens Res. 2015;38:776-82.

23. Hosaka M, Asayama K, Staessen JA, Ohkubo T, Hayashi K, Tatsuta N, et al. Breastfeeding leads to lower blood pressure in 7-year-old Japanese children: Tohoku Study of Child Development. Hypertens Res. 2013;36:117-22.

24. Satoh M, Kikuya M, Ohkubo T, Imai Y. Acute and subacute effects of the great East Japan earthquake on home blood pressure values. Hypertension. 2011;58:e193-4.

25. Tanaka M, Imai J, Satoh M, Hashimoto T, Izumi T, Sawada S, et al. Impacts of the Great East Japan Earthquake on diabetic patients. J Diabetes Investig. 2015;6:577-86

26. Tanaka M, Imai J, Satoh M, Hashimoto T, Izumi T, Sawada S, et al. Glycemic control in diabetic patients with impaired endogenous insulin secretory capacity is vulnerable after a natural disaster: study of Great East Japan Earthquake. Diabetes Care. 2014;37:e212-3.

27. Aoki T, Fukumoto Y, Yasuda S, Sakata Y, Ito K, Takahashi J, et al. The Great East Japan Earthquake Disaster and cardiovascular diseases. Eur Heart J. 2012;33:2796-803

28. Nishizawa M, Hoshide S, Shimpo M, Kario K. Disaster hypertension: experience from the great East Japan earthquake of 2011. Curr Hypertens Rep. 2012:14:375-81.

29. Imai Y, Kario K, Shimada K, Kawano Y, Hasebe N, Matsuura H, et al. The Japanese Society of Hypertension Guidelines for Self-monitoring of Blood Pressure at Home (Second Edition). Hypertens Res. 2012;35:777-95.

\section{Submit your next manuscript to BioMed Central and we will help you at every step:}

- We accept pre-submission inquiries

- Our selector tool helps you to find the most relevant journal

- We provide round the clock customer support

- Convenient online submission

- Thorough peer review

- Inclusion in PubMed and all major indexing services

- Maximum visibility for your research

Submit your manuscript at www.biomedcentral.com/submit
C) Biomed Central 